\title{
ANALYSIS OF ADVERSE DRUG REACTION IN A TERTIARY CARE HOSPITAL: A RETROSPECTIVE STUDY
}

\section{DOLLY ROY, AYAN PURKAYASTHA*, ROHIT TIGGA}

Department of Pharmacology, Silchar Medical College and Hospital, Silchar, Assam, India. Email: ayanp007@gmail.com

Received: 28 September 2016, Revised and Accepted: 07 October 2016

\section{ABSTRACT}

Objectives: Adverse drug reaction (ADR) is an important cause of morbidity, mortality, and prolonged hospitalization. The objective of this study is to measure the incidence, types, and nature of ADR in a tertiary care hospital located in Silchar, Assam.

Methods: A retrospective noninterventional analysis of all ADRs reported by ADR Monitoring Centre, Department of Pharmacology, Silchar Medical College, from March 2014 to February 2015 was performed. A total of 162 predesigned forms were used for collection of data. All forms were duly checked for completeness, if not, they were rejected.

Results: A total of 162 forms were assessed of which 96 (59\%) were females and 66 (41\%) were males. The distribution of ADRs in different age groups were found to be $3(1.85 \%)$ in $0-15$ years, 71 (43.82\%) in 16-30 years, 65 (40.12\%) in 31-45 years, 8 (4.93\%) in $46-60$ years, and 15 (9.25\%) in age group >60 years. $150(92.6 \%)$ of the ADRs were serious and $12(7.4 \%)$ were not serious. As per the World Health Organization causality assessment scale, 120 (74.07\%) were probable and 42 (25.92\%) were possible. The most common ADR was anaphylactic reaction (AR) in 69 (42.59\%) patients. The drugs which commonly caused ADR were iron sucrose infusions, nevirapine, cephalosporins, antiprotozoals, nonsteroidal anti-inflammatory drugs, and quinolones followed by others.

Conclusion: The majority of ADRs were probable. The most common ADR was AR caused by iron sucrose infusion. Different drugs caused different ADRs. ADRs thereby increase morbidity and mortality in patients as well as socioeconomic burden.

Keywords: Adverse drug reaction, Anaphylactic reaction, Iron sucrose infusion, Noninterventional, Retrospective analysis.

(C) 2017 The Authors. Published by Innovare Academic Sciences Pvt Ltd. This is an open access article under the CC BY license (http://creativecommons. org/licenses/by/4. 0/) DOI: http://dx.doi.org/10.22159/ajpcr.2017.v10i1.15439

\section{INTRODUCTION}

The World Health Organization (WHO) defines an adverse drug reaction (ADR) as - a reaction to a drug which is harmful and unintentional and which occurs at doses usually used in man for the prophylaxis, identification or treatment of disease or for the alteration of physiological function [1]. It is well-known that an ADR is one of the major causes of hospitalization, and each drug has probable adverse effects as well as interaction with other substances [2]. The risk of ADRs is governed by several factors such as dose and frequency of administration, genetic, and pharmacokinetic characteristics of special populations such as children and elderly patients and those with liver or kidney diseases [3]. ADRs are classified into six types: Dose-related (augmented), nondose-related (bizarre), dose-related and time-related (chronic), time-related (delayed), withdrawal (end of use), and failure of therapy (failure) [4]. In the recent years, there has been a considerable rise in the reporting of undesirable events. However, a concern regarding the causal relationship between the drug and adverse event remains and is of paramount importance in the present state of emerging adverse events [5]. The causality assessment system proposed by the WHO Collaborating Center for International Drug Monitoring, the WHO-Uppsala Monitoring Centre (UMC), and the Naranjo probability Scale are the commonly established and extensively used means for causality assessment as they are simple and easily understandable [6]. ADRs add to undue health-care costs by increasing morbidity and duration of hospitalization in patients. It also leads to mortality at times. Hence, there is an imperative need to generate understanding among physicians and the population toward ADR monitoring [7]. Owing to the need of the situation, we conducted a retrospective study to measure the incidence, types, and nature of ADR in a tertiary care hospital located in Silchar, Assam.

\section{METHODS}

A total of 162 predesigned forms were used for collection of data during the period from March 2014 to February 2015. The study was conducted in the Department of Pharmacology, Silchar Medical College and Hospital, Silchar, Assam. Only the forms that were filled up were included in our study. The study was duly approved by the Institutional Ethics Committee. Causality assessment was done using the WHO-UMC causality assessment scale. Statistical analysis was performed using Chi-square test; $\mathrm{p}<0.05$ was considered to be significant.

\section{RESULTS}

A total of 162 forms were collected and analyzed. Out of 162, 96 (59\%) were females and 66 (41\%) were males (Fig. 1). The distribution of ADRs in different age groups was found to be $3(1.85 \%)$ in $0-15$ years, $71(43.82 \%)$ in $16-30$ years, $65(40.12 \%)$ in $31-45$ years, $8(4.93 \%)$ in 46-60 years, and $15(9.25 \%)$ in age group $>60$ years (Fig. 2). Out of 162 ADRs, 150 (92.6\%) of the ADRs were serious and 12 (7.4\%) were not serious (Fig. 3); $p$ value was highly significant $(\mathrm{p}<0.0001)$. Causality assessment was done on the WHO-UMC causality assessment scale, $120(74.07 \%)$ were probable and 42 (25.92\%) were possible (Fig. 4).

The most frequent ADR was anaphylactic reaction (AR) which occurred in $69(42.59 \%)$ patients. A maculopapular rash was observed in $20(12.34 \%)$ patients, erythematous rash in $15(9.25 \%)$ patients, urticarial rash in $10(6.17 \%)$ patients, extrapyramidal symptom in $6(3.7 \%)$ patients, fixed drug eruption in $5(3.08 \%)$ patients, StevenJohnson syndrome in $4(2.46 \%)$ patients, toxic epidermal necrolysis in $3(1.85 \%)$ patients, and others such as respiratory discomfort, itching, fever, and vomiting in 30 (18.51\%) patients (Fig. 5). 


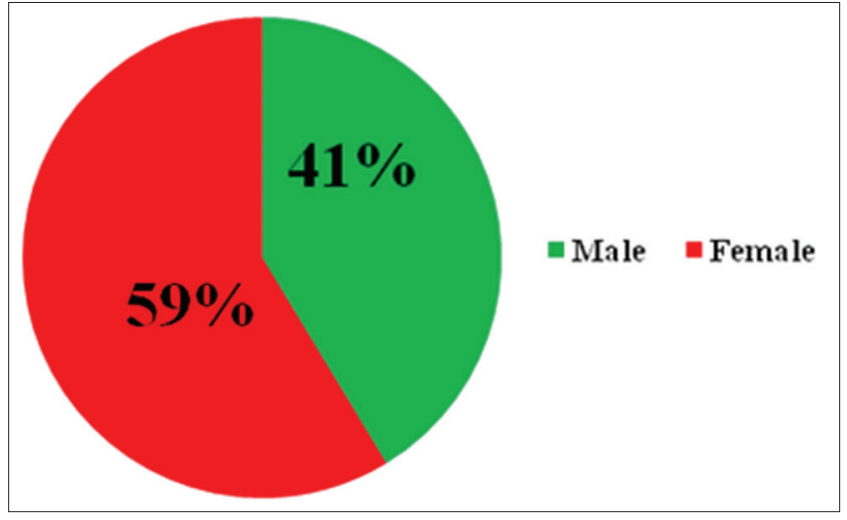

Fig. 1: The distribution of gender

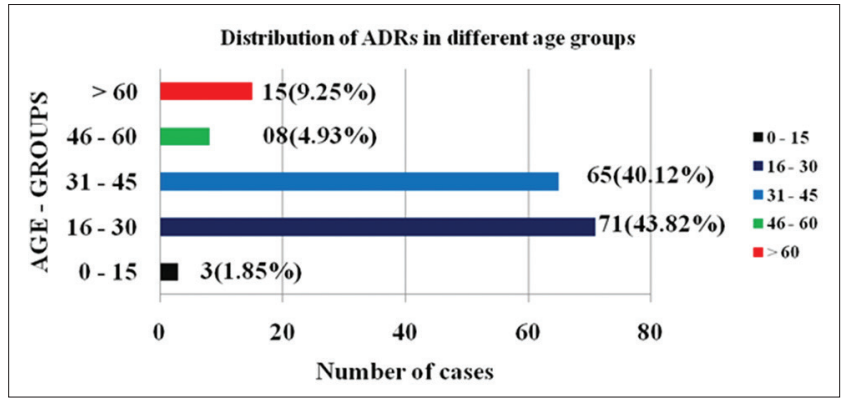

Fig. 2: The age group distribution

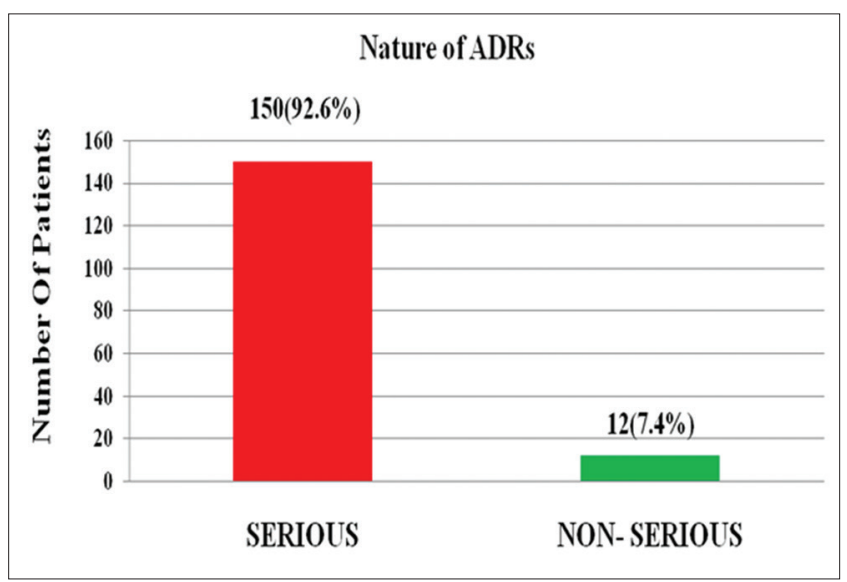

Fig. 3: The nature of seriousness of adverse drug reactions

Out of 69 ARs, 33 (47.82\%) was caused by iron sucrose infusions, $16(23.18 \%)$ were caused by amino acid derivative infusions, $9(13.04 \%)$ each occurred from the use of human albumin and antimicrobial infusions, and 1 (1.44\%) each from blood transfusion and dextrose-normal saline infusion (Fig. 6).

Other adverse effects are summarized as in (Table 1).

\section{DISCUSSION}

Our study was a retrospective analysis of ADR conducted in the Department of Pharmacology, Silchar Medical College and Hospital, Silchar, Assam. In our study, we found that females (59\%) were more commonly affected by ADRs than males (41\%). However, Shamna et al. (2014) and Patel and Marfatia (2008) in their study found that males were mostly affected. This difference may be because of the fact that in our institution a significant number of ADRs were reported from the department of obstetrics and gynecology as compared to other clinical departments $[8,9]$. The majority

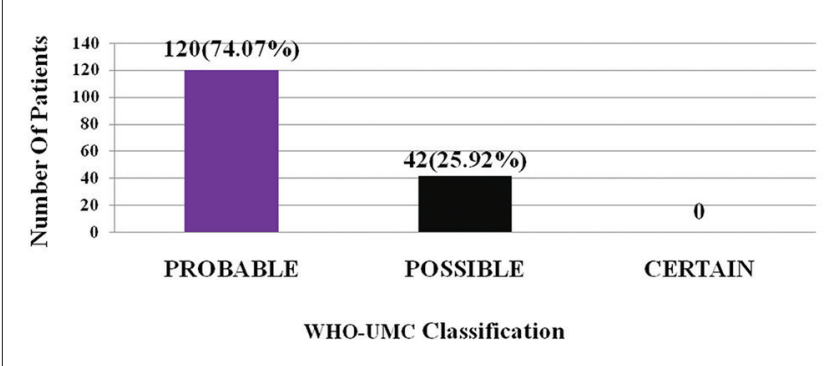

Fig. 4: The causality assessment classification as per the World Health Organization-Uppsala Monitoring Centre causality assessment scale

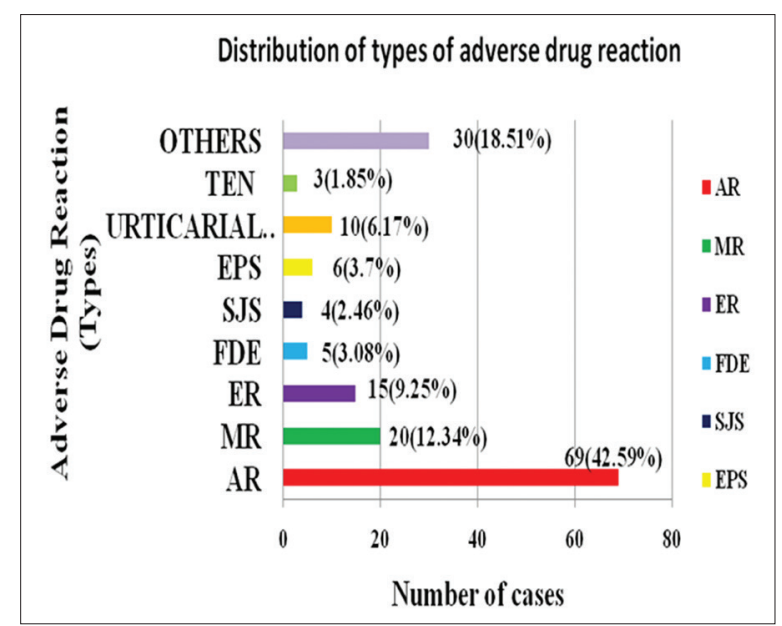

Fig. 5: The distribution of different types of adverse drug reaction

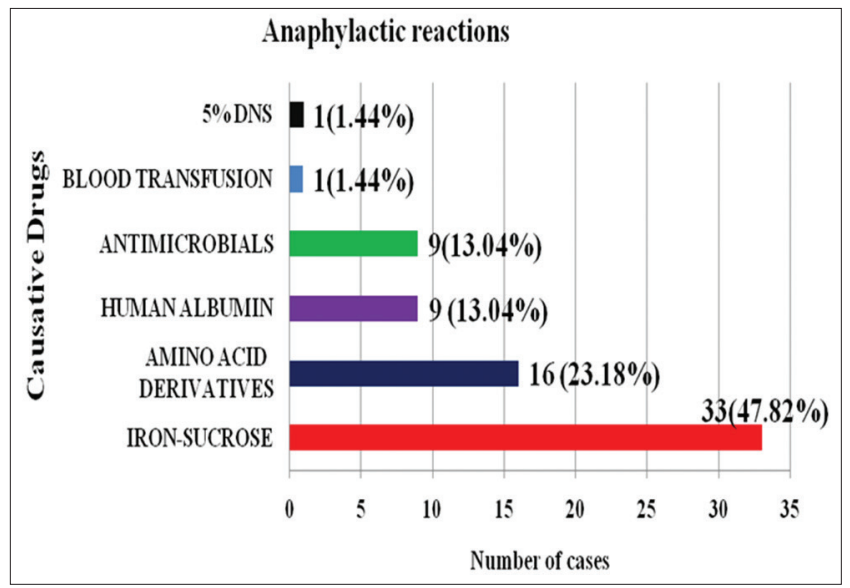

Fig. 6: The distribution of drugs causing anaphylactic reaction

of ADRs were seen in age group of 16-30 years. Similar findings were revealed by Sharma et al. (2001) in their study [10].

The causality assessment was done using the WHO-UMC causality assessment scale. Out of 162 ADRs, 120 (74.07\%) were probable and $42(25.92 \%)$ were possible. This was comparable to the earlier metaanalysis by Lazarou et al. (1998) where bulk of the ADRs was of serious type [11].

In our study, we found that most common ADR was AR which was caused by iron sucrose infusion. Rampton et al. (2014) and Sav et al. (2007) in their respective study observed that iron sucrose infusions were associated with ARs [12,13]. 
Table 1: The different adverse reactions and the most common drug causing them as per our study

\begin{tabular}{ll}
\hline Adverse reaction & Most common drug \\
\hline MR & Antiviral (nevirapine) \\
ER & $\begin{array}{l}\text { Antibacterials (amoxicillin-clavulanic } \\
\text { acid, piperacillin+tazobactam, } \\
\text { levofloxacin, cefixime, ceftriaxone) }\end{array}$ \\
& $\begin{array}{l}\text { Fixed-dose combination drugs } \\
\text { such as (ofloxacin+ornidazole, }\end{array}$ \\
FDE & ciprofloxacin+ornidazole) \\
& $\begin{array}{l}\text { Antibacterials (ceftazidime, } \\
\text { ciprofloxacin) }\end{array}$ \\
UR & Nonsteroidal anti-inflammatory \\
& drug (paracetamol) \\
SJS & Nonsteroidal anti-inflammatory \\
& drug (nimesulide) \\
TEN & Amino acid derivatives \\
Others such as fever, & \\
vomiting, and respiratory & \\
discomfort &
\end{tabular}

MR: Maculopapular rash, ER: Erythematous rash, FDE: Fixed drug eruptions, UR: Urticarial rash, SJS: Steven-Johnson Syndrome, TEN: Toxic epidermal necrolysis

The most common offending drugs responsible for ADRs were iron sucrose infusions in $20.37 \%$. This was followed by fluoroquinolones, penicillins, and cephalosporins. Stavreva et al. (2008) in their revealed that the predominance of cephalosporins and Hussain et al. (2010) in their study found that fluoroquinolones were most accounted for ADR, whereas Priyadharsini et al. (2011) in their study found penicillin to be the most common drug causing ADR [14-16].

\section{CONCLUSION}

ADRs are among the foremost causes of morbidity, mortality, and prolonged hospitalization in patients. The results that we have obtained in our study offer an insight to the health-care professionals on the significance of scrutinizing and reporting of ADRs. It is essential for the health-care system to endorse the unprompted reporting of ADRs, suitable documentation and episodic reporting to regional or national pharmacovigilance centers to warrant drug safety. It is very important to plan the method of ADR monitoring in such a way that it gives confidence to clinicians, other medical and health-care personnel to report ADRs spontaneously and extensively.

\section{ACKNOWLEDGMENT}

We would like to thank Dr. Pinaki Chakravarty, Associate Professor and i/c, ADR Monitoring Centre, Department of Pharmacology, Silchar
Medical College and Hospital and Mr. Babul Dewan, Technical Associate, ADR Monitoring centre, Department of Pharmacology, Silchar Medical College and Hospital, for their continuous help and guidance during the course of our study.

\section{REFERENCES}

1. Alam N, Kumar R, Bhardwaj A. Pharmacovigilance for adverse drug reactions in patients on non-steroidal anti-inflammatory drugs and hepatic dysfunction in aceclofenac therapy in South Delhi hospital. Int J Pharm Pharm Sci 2012;4 Suppl 5:128-31.

2. Kumar L. Pharmacovigilance/reporting adverse drug reactions: An approach to enhance health surveillance and extending market share by minimizing the chances of drug withdrawals. Int J Pharm Pharm Sci 2015;7(9):1-7.

3. Sultana J, Cutroneo P, Trifirò G. Clinical and economic burden of adverse drug reactions. J Pharmacol Pharmacother 2013;4 Suppl 1:S73-7.

4. Edwards IR, Aronson JK. Adverse drug reactions: Definitions, diagnosis, and management. Lancet 2000;356(9237):1255-9.

5. Naidu RP. Causality assessment: A brief insight into practices in pharmaceutical industry. Perspect Clin Res 2013;4(4):233-6.

6. Zaki SA. Adverse drug reaction and causality assessment scales. Lung India $2011 ; 28(2): 152-3$.

7. Davies EC, Green CF, Taylor S, Williamson PR, Mottram DR, Pirmohamed M. Adverse drug reactions in hospital in-patients: A prospective analysis of 3695 patient-episodes. PLoS One 2009;4(2):e4439.

8. Shamna M, Dilip C, Ajmal M, Linu Mohan P, Shinu C, Jafer CP, et al. A prospective study on adverse drug reactions of antibiotics in a tertiary care hospital. Saudi Pharm J 2014;22(4):303-8.

9. Patel RM, Marfatia YS. Clinical study of cutaneous drug eruptions in 200 patients. Indian J Dermatol Venereol Leprol 2008;74(4):430.

10. Sharma VK, Sethuraman G, Kumar B. Cutaneous adverse drug reactions: Clinical pattern and causative agents - A 6 year series from Chandigarh, India. J Postgrad Med 2001;47(2):95-9.

11. Lazarou J, Pomeranz BH, Corey PN. Incidence of adverse drug reactions in hospitalized patients: A meta-analysis of prospective studies. JAMA 1998;279(15):1200-5.

12. Rampton D, Folkersen J, Fishbane S, Hedenus M, Howaldt S, Locatelli $\mathrm{F}$, et al. Hypersensitivity reactions to intravenous iron: Guidance for risk minimization and management. Haematologica 2014;99(11):1671-6.

13. Sav T, Tokgoz B, Sipahioglu MH, Deveci M, Sari I, Oymak O, et al. Is there a difference between the allergic potencies of the iron sucrose and low molecular weight iron dextran? Ren Fail 2007;29(4):423-6.

14. Stavreva G, Pendicheva D, Pandurska A, Marev R. Detection of adverse drug reactions to antimicrobial drugs in hospitalized patients. Trakia J Sci 2008;6(1):7-9.

15. Hussain MM, Girhepunje K, Pal R, Siddiqua SS. Incidence of adverse drug reactions in a tertiary care hospital: A systematic review and metaanalysis of prospective studies. Der Pharm Lett 2010;2(3):358-68.

16. Priyadharsini R, Surendiran A, Adithan C, Sreenivasan S, Sahoo FK. A study of adverse drug reactions in pediatric patients. J Pharmacol Pharmacother 2011;2:277-80. 